\title{
As origens da Embraer
}

Maria Cecilia Spina Forjaz

É tempo de se instalar uma escola de verdade em um campo adequado. N ão é difícil encontrá-lo no Brasil [...] margeando a linha da Central do Brasil, especialmente nas imediações de M ogi das Cruzes, avistam-se campos que me parecem bons. SANTOS DUMONT, 1918

A Empresa Brasileira de Aeronáutica S/A, Embraer, foi fundada em 1969, durante o regime militar. Era a concretização deum antigo projeto de militares da Aeronáutica de constituir uma indústria aeronáutica no país. Esse projeto estratégico dos oficiais da Força Aérea Brasileira estava ligado à problemática da Segurança N acional e relacionava-se com 0 amplo engajamento dos militares no processo político brasileiro.

$N$ esse sentido, em sua origem, a Embraer assemelha-se às indústrias petrolífera e siderúrgica, que também contaram com ativa participação dos militares na sua instalação. Como a Embraer, a Petrobrás e a Companhia Siderúrgica $\mathrm{N}$ acional foram gestadas durante 0 Estado N ovo esignificaram um pacto entre militares e lideranças civis vinculadas ao nacionalismo desenvolvimentista da era Vargas, quando o Estado brasileiro assumiu a iniciativa de criar uma infra-estrutura de energia, transportes, siderurgia e comunicações para sustentar o projeto de industrialização nacional.

D e fato, já desde a Revolução de 1932 lideranças militares associadas a Vargas, encabeçadas pelos generais Pedro Aurélio de Góes M onteiro e 
Eurico G aspar D utra, começaram a intuir os vínculos entre potência industrial e potência militar. Perceberam que a Segurança N acional, à época chamada "D efesa N acional", dependia, em grande medida, de um projeto mais amplo de industrialização nacional conduzida pelo Estado. Assim, a doutrina político-militar do Estado $\mathrm{N}$ ovo e as exigências de ampliação da defesa nacional, decorrentes da Segunda Guerra M undial, nutriram o ambienteno qual a arma mais nova das Forças Armadas, a Aeronáutica, começou a planejar o seu futuro. D esse modo, nos anos de 1940 e de 1950 foram criados a FAB, o M inistério da Aeronáutica, o Instituto Tecnológico de Aeronáutica (ITA) e o Centro Tecnológico de Aeronáutica (CTA), instituições que formaram o embrião da Embraer. Ao recuperar essa origem remota, retomaremos os elos, pouco explorados na literatura, entre indústria aeronáutica e o projeto político dos militares.

A criação da FAB e do Ministério da Aeronáutica

O s primeiros passos no longo processo que levou à criação da Aeronáutica brasileira remontam aos anos de 1920, quando foi instituída a arma da aviação, ao lado das outras armas tradicionais do Exército, artilharia, cavalaria e infantaria. Estávamos então no ano de 1927.

O s poucos cadetes que escolhiam essa nova arma tinham que ir para a Escola de Aviação M ilitar do C ampo dos Afonsos, onde permaneciam isolados e perdiam o contato com o Exército. Ali desenvolviam um éthos militar diferente, baseado no individualismo, no espírito de aventura ena coragem exacerbada exigidos de futuros pilotos. Q ueremos com isso sugerir que os cadetes que buscavam a aviação tinham menos apego à disciplina eà obediência, características próprias do espírito militar.

Entretanto, apesar de al guns traços particulares dos aviadores, distintos dos dos soldados, as doutrinas estrangeiras que orientaram a modernização do Exército, nos anos de 1920, também balizaram a formação dos futuros oficiais da Aeronáutica. A organização da aviação do Exército era similar à francesa e fora implantada sob influência da M issão M ilitar Francesa de Aviação, chefiada pelo coronel Etienne $M$ agnin, que foi também o primeiro diretor de ensino da Escola de Aviação M ilitar. A lei que criou a aviação militar previu também o controle dessa arma por um oficial-general do Exército, mantendo-a subordinada à sua hegemonia.

Já existia, então, a aviação naval, que todavia se pautava por um sistema diferente, já que só podia integrá-la quem tivesse se formado na Escola 
$\mathrm{N}$ aval e fosse primeiro-tenente. $\mathrm{A}$ influência estrangeira dominante nesse caso foi a norte-americana; a M issão $\mathrm{N}$ aval Americana esteve no Brasil entre 1922 e 1931, orientando a organização administrativa, a instrução técnica e o treinamento do pessoal.

A aviação, portanto, além de arma incipiente, estava dividida entre Exército e $M$ arinha, e não possuía nenhuma autonomia administrativa, operacional ou técnica. Seus quadros eram reduzidos e seus componentes considerados indisciplinados e individualistas. Sua autonomia começou a ser conquistada depois da Revolução de 1930, quando o major-aviador Plínio Raulino de O liveira assumiu o comando da Escola de Aviação M ilitar. A partir de então, só foram nomeados comandantes aviadores. $M$ as o passo decisivo seria dado um pouco mais tarde, com a criação do M inistério da Aeronáutica e da Força Aérea Brasileira, nos anos de 1940, sob a influência do novo contexto geopolítico, estratégico e tecnológico da Segunda G uerra M undial.

A rigor, a utilização de aviões como instrumentos de ataque e defesa tivera seu início na Primeira G uerra M undial, quando nasceram as tecnologias e as doutrinas militares sobre a importância da força aérea. $M$ as, mesmo entre os países desenvolvidos, o uso da aviação em enfrentamentos bélicos só se consolidou na Segunda Guerra, quando a aviação militar passou a ser decisiva para as estratégias de ataque e defesa das nações belige rantes, tanto entre os Aliados, como entre os países do Eixo.

No Brasil, o debate em torno da criação de uma força aérea e de um "M inistério do Ar", expressão utilizada nos anos de 1930, é indissociável das doutrinas militares européias sobre segurança nacional, as primeiras a influenciar o desenvolvimento da aeronáutica no Brasil. Tais doutrinas propugnavam que a supremacia militar - e, portanto, a superioridade sobre o inimigo e a capacidade de vencer as guerras - estava condicionada à utilização em larga escala da aviação militar¹. D a Europa vieram também os modelos das primeiras experiências de criação de M inistérios da Aeronáutica, ocorridas na Itália, na Inglaterra e na França.

Às influências européias vieram somar-se as doutrinas norte-americanas, que chegaram depois, já que o desenvolvimento da força aérea nos Estados U nidos foi posterior ao europeu. N esse país, o primeiro a formular a idéia da necessidade de uma aviação forte para vencer as guerras foi W illiam M itchell, comandante da aviação norte-americana na Primeira Guerra M undial. Ele foi afastado das Forças Armadas por insubordinação e durante algum tempo os americanos se desinteressaram pelo assunto. 0
1.Um dos pioneiros idealizadores dessas novas teorias militares foi o general italiano Giulio D ouhet, quecomandou o primeiro batalhão de aviação da Itália entre 1912 e 1915. 
2.0 s Estados Unidos não têm atéhojeum $\mathrm{M}$ inistério daAeronáutica. coronel Alexander Seversky, piloto de caça da Rússia czarista, foi outro importante pioneiro da idéia da supremacia da aviação sobre as outras armas nas guerras modernas, isto é, posteriores à Primeira Guerra M undial. D epois da revolução russa ele emigrou para os Estados U nidos, onde se tornou um premiado projetista de aviões. $M$ as foi 0 ataque japonês à base naval de Pearl $\mathrm{H}$ arbour, em dezembro de 1941, o evento responsável por tornar flagrantes para os Estados U nidos a necessidade e a importância crucial da aviação nas guerras modernas. Foi justamente durante a guerra que se criou a Força Aérea do Exército Americano, a U saf².

No caso brasileiro, o desperdício decorrente da existência de três aviações operando e sendo gerenciadas em separado - a da M arinha, a do Exército e a aviação comercial - constituiu-se num dos principais argumentos em favor da criação do M inistério. Ao mesmo tempo, a evolução tecnológica da indústria aeronáutica e de armamentos tornava a aviação um instrumento cada vez mais importante na defesa nacional, principalmente num país de dimensões continentais e totalmente carente de infraestrutura de transportes e comunicações. M as não se deve deixar de ter em conta também o papel hegemônico das Forças Armadas na sustentação do regime varguista e na implementação de um projeto estratégico de desenvolvimento nacional baseado na industrialização e na construção de um forte sistema de defesa nacional. $N$ ão é por acaso que a criação da Aeronáutica ocorre durante a Segunda G uerra M undial, quando aumentam as preocupações dos militares e das elites políticas com a vulnerabilidade brasileira. $\mathrm{N}$ ão só as Forças Armadas eram mal equipadas, como faltava infraestrutura de transportes, comunicações e energia, fundamental para a de fesa nacional e para a industrialização do país.

Alemanha eEstados U nidos disputavam a adesão brasileira para fortalecer seu poderio militar no Atlântico sul, ea elite dirigente do Estado N ovo, assim como as Forças Armadas brasileiras, dividiram-se em facções germanófilas e americanófilas. G etúlio Vargas acabou optando pela adesão aos norte-americanos em troca de financiamento para a construção da usina de Volta Redonda. Foi uma decisão pragmática de política externa que implicou grande aproximação com a potência norte-americana e grandeaumento de sua influência militar e econômica sobre o Brasil:

Em meados de 1940, o governo norte-americano, após inúmeras marchas e contramarchas, finalmente deslanchou um programa de aproximação aeronáutica com os países da América Latina. Por sua posição estratégica, o Brasil mereceu 
uma atenção especial [...]. N essa ocasião, vários oficiais militares e profissionais civis foram enviados aos Estados U nidos para fazerem cursos de especialização em Aeronáutica (Botelho, 1999, p. 142).

O s vizinhos argentinos, sob o regime peronista, mantiveram uma neutralidade aparente, que de fato buscava encobrir 0 apoio de Perón a $\mathrm{H}$ itler, dequem comprou armas, tanques eaviões para usá-los numa possível guerra com o Brasil, caso este aderisse aos Aliados. Embora a invasão argentina não tenha acontecido, o Brasil esteve na mira dos submarinos alemães. $\mathrm{A}$ guerra tornou muito mais evidente a fragilidade das Forças Armadas, em seu despreparo para enfrentar ameaças de agressões externas, assim como a falta de autonomia brasileira diante do poderio norte-americano, que instalara várias bases militares espal hadas pelo território nacional.

D epois da adesão do regime Vargas, o general Eurico Gaspar Dutra alertou para o perigo de "cedermos a nossos aliados armados os mares, 0 céu e os campos de nossa terra que, desarmados, não podemos defender, como devêramos" (C outinho, 1955, p. 341). N um país de dimensões continentais, com uma costa imensa e rios extensos, a defesa nacional passou a exigir além do Exército e da $M$ arinha a criação de uma Força Aérea que garantisse as fronteiras e o espaço aéreo. Finalmente, depois de amplo debate e campanhas na imprensa, G etúlio Vargas assinou o D ecreto 2961, em 20 de janeiro de 1941, criando o M inistério da Aeronáutica e estabele cendo a fusão das aviações do Exército e da $M$ arinha numa só corporação, denominada Forças Aéreas $\mathrm{N}$ acionais, subordinadas ao novo $\mathrm{M}$ inistério e que teria seu nome mudado para Força Aérea Brasileira pelo D ecreto-lei 3302, de maio de 1941.

A estrutura da Aeronáutica brasileira não seguiu fielmente os modelos estrangeiros:

Segundo a doutrina brasileira, tudo o que se locomove no ar equem pilota pertencem ao M inistério da Aeronáutica. Trata-se de uma solução completamente diferente da que os americanos adotaram. A credito que somos o único país que juntou todas as aviações em um único ministério [...]. 0 M inistério da Aeronáutica mantém controle total sobre o sistema, monitorando permanentemente as aviações, inclusive a aviação civil [...]. N os Estados Unidos, cada uma das cinco aviações possui sistema próprio, controla seus aviões no ar, mas ignora o que ocorre com os demais. N enhuma força quer se submeter à outra, é uma briga medonha, uma confusão desgraçada (M oura, 1996, p. 98)! 
A doutrina político-militar subjacente à criação do novo M inistério pode ser resumida nas seguintes concepções:

- Comando único, político e estratégico, sobrepondo-se a todas as atividades aeronáuticas do pás, civis e militares;

- Integração de órgãos dispersos em três M inistérios com atividades absolutamente correlatas;

- Integração de infra-estrutura aeronáutica para uso comum, civil e militar, com grande economia de meios;

- Lançamento das bases para implantação definitiva da indústria aeronáutica brasileira;

- Institucionalização da pesquisa, com vistas ao desenvolvimento tecnológico (I nstituto H istórico-Cultural da Aeronáutica, 1990, p. 74).

Vêse, pelo trecho citado, que o grupo de militares que liderou a criação daFAB edo M inistério da Aeronáutica tinha como objetivos, jáno início dos anos de 1940, a constituição de uma indústria aeronáutica nacional eo domínio da tecnologia necessária para isso. N ão sem razão, o grupo apoiava e tinha apoio de G etúlio Vargas e, além das pressões que exercia dentro do governo, foi protagonista de intensa campanha na imprensa em defesa da autonomia da força aérea.

A escolha de Joaquim Pedro Salgado Filho, um civil, como ministro da Aeronáutica revelou a sagacidade política do ditador, empenhado em evitar os manifestos conflitos de interesse entre as aviações do Exército e da M arinha. Vargas furtou-se a tomar partido e nomeou um político gaúcho de sua confiança, ex-deputado federal e ministro do Trabalho, com o que facilitou 0 entrosamento entre as armas e obteve 0 controle político da nova instituição.

Salgado Filho e a equipe do M inistério participavam das correntes militares favoráveis a uma aproximação com os Estados Unidos, e por isso intensificaram as negociações com vistas a uma maior colaboração entre os dois países, evidentemente desejada pela potência norte-americana. 0 interesse maior para o Brasil era o aparelhamento da Força Aérea e o treinamento de seus quadros, já que o país não dispunha de aviões de instrução suficientes para a formação de novos pilotos nem de instituições de ensino adequadas para 0 treinamento militar.

Em junho de 1941, Brasil e Estados Unidos assinaram um acordo de cooperação baseado no L end and Lease Act, que regulava os programas 
de empréstimos e arrendamentos subsidiados, por meio dos quais os Estados U nidos forneciam ajuda militar aos países aliados. Foram trazidos mais de quatrocentos aviões de treinamento e quase todos os oficiais da Aeronáutica na época fizeram um curso de estado-maior nosEstados U nidos. A contrapartida brasileira foi a permissão para a instalação de várias bases militares norte-americanas em território nacional: Amapá, Belém, São Luís do $\mathrm{M}$ aranhão, Fortaleza, Recife e $\mathrm{N}$ atal, a maior e mais importante delas, que chegou a contar com 60 mil homens.

A Força Aérea, apesar de abrigar al guns integralistas simpáticos ao Eixo, era majoritariamente favorável aos Aliados e seus oficiais apoiaram integralmente a participação brasileira na Segunda Guerra M undial. As palavras do brigadeiro $\mathrm{N}$ ero $\mathrm{M}$ oura informam sobre a escassa porcentagem de oficiais da Aeronáutica que participaram do movimento integralista:

0 integralismo estava organizado em legiões, seções e regimentos. A seção dos Afonsos tinha como chefe um barbeiro, o Barbosa, velhote simpático e agradável. Ele era 0 chefão, a quem 0 ex-ministro M árcio de Souza e M elo, então major, conhecido e sabido como integralista, obedecia - era engraçado! 0 Rui Presser Bello, que já morreu, também era integralista, e havia outros insignificantes, de cujo nome não guardo lembrança (M oura, 1996, p. 85).

Os embriões da indústria de aviação:

Centro Tecnológico de Aeronáutica e o Instituto Tecnológico de Aeronáutica

0 projeto estratégico da Aeronáutica, do qual derivou posteriormentea fundação da Embraer, priorizou a formação de recursos humanos de alto nível, capazes não só de absorver os conhecimentos tecnológicos que surgiam de forma acelerada no cenário internacional, mas também de buscar soluções adequadas ao contexto nacional, numa época em que o Brasil se caracterizava por uma economia predominantemente agrícola e, portanto, altamente dependente dos produtos industrializados vindos do exterior. As lideranças da Aeronáutica sabiam da impossibilidade de montar uma indústria aeronáutica naquele estágio de desenvolvimento da economia brasileira. Assim, para ajudar a criar as condições necessárias para seu estabelecimento no futuro, optaram por desenvolver antes uma escola de engenharia aeronáutica e um centro de pesquisa sobre tecnologia aeronáutica.

Com uma visão quase profética, os pioneiros da Aeronáutica conceberam um centro de pesquisas que tivesse como núcleo uma avançada escola 
3.U m exemplo marcante desse esforço foi a contratação do professor $\mathrm{H}$ enrich Fockee sua equipe, que transplantaram para o país conhecimentos avançados no campo aeronáutico no início da década de 1950. Posteriormente a maioria dos alemães voltou para a Europa, ondea demanda por cientistas era enorme devido à recuperação econômica que se seguiu à guerra. de engenharia, deforma a assegurar o desenvolvimento auto-sustentado do setor aeronáutico, com frutos que se estenderiam, a médio prazo, ao parque industrial brasileiro e às atividades da aviação civil. D esse modo, em um país com uma infra-estrutura industrial mínima, incapaz de fabricar atébens de consumo leve, iniciava-se a formação de engenheiros aeronáuticos altamente qualificados, o que daria origem a novas especializações em eletrônica, mecânica e infra-estrutura aeronáutica, ea um conjunto de instituições indutoras do moderno desenvolvimento tecnológico brasileiro.

Paralelamente às atividades voltadas para a formação de recursos humanos no ITA, os idealizadores do CTA, sob a liderança do então major-aviador Casimiro M ontenegro Filho, criaram um centro depesquisas capaz de, a curto prazo e de forma pragmática, trazer para o país al gumas das tecnologias emergentes no exterior e que acelerariam o desenvolvimento da indústrialocal ${ }^{3}$. N os laboratóriosisolados instalados no campus do CTA, em São Josédos $C$ ampos, iniciaram-setrabal hos pioneiros de prospecção tecnológica e aplicação de novas técnicas, estimulando o surgimento de pequenas indústrias, num modelo decírculos concêntricosem queo núcleo opera como matriz supridora de recursos humanos e suporte laboratorial para os novos empreendedores. 0 ITA e o CTA tornaram-se irradiadores de tecnologia, permitindo sua fixação, e atuaram como suporte para a criação de inúmeras empresas, em geral fundadas por "iteanos", das quaisa mais importante delas viriaa ser a Embraer. Ao longo dosanos, seuslaboratórios evoluíram para estruturas mais complexas, em função da demanda e dos novos conhecimentos, dando lugar aos três institutos atual menteexistentes: o I nstituto de Aeronáutica e Espaço (IAE), o Instituto de Estudos Avançados (IEAv) e o Instituto de Fomento e Coordenação Industrial (IFI). Vejamos como tal processo transcorreu.

Logo após o fim da Segunda Guerra M undial, um grupo de oficiais da Aeronáutica, liderado pelo brigadeiro Casimiro M ontenegro Filho e no qual se incluíam Aldo Vieira da Rosa, George M oraes, O swaldo N ascimento Leal e muitos outros, começou a planejar a criação de uma instituição voltada para o desenvolvimento da indústria aeronáutica no Brasil.

Esse grupo tinha antigas vinculações com a aviação, anteriores à criação da Aeronáutica, e acumulara ampla experiência internacional, principalmente no MIT, onde vários deles estudaram. A figura central era, sem dúvida, o brigadeiro Montenegro, revolucionário de 1930 advindo dos tempos da aviação do Exército. Tinha fama de excelente administrador, pois comandara, com sucesso, o D estacamento Aeronáutico de São Paulo 
na década de 1930, ocasião em que estabelecera ligações com os industriais paulistas que estavam tentando criar uma incipiente indústria de aviões. Ele foi o primeiro brasileiro a se aproximar do eminente físico norte-americano Richard Smith, chefe do D epartamento de Aerodinâmica do M assachusetts Institute of Technology (M IT) e futuro mentor do ITA.

$M$ ontenegro e sua equipe entraram em negociações com o professor Smith e elaboraram um plano cujas idéias básicas formavam uma pauta a ser desenvolvida. 0 Brasil, como país pobre de combustíveis e com baixo padrão de vida, deveria procurar desenvolver tipos de avião cuja principal característica fosse a economia; os aviões norte-americanos e ingleses eram dispendiosos, pois neles se procurava reunir grande velocidade de cruzeiro ao máximo de conforto para os usuários, além de utilizarem motores leves e, portanto, dispendiosos, devido ao grande consumo de combustível; países importadores de petróleo, como o Brasil, deveriam utilizar motores mais pesados e mais econômicos. 0 Brasil não deveria receber, mesmo que gratuitamente, material aeronáutico de guerra, a não ser para atendimento de necessidades imediatas, pois, caso contrário, ficaria de posse de grande quantidade de material antiquado, caro para manter e dispendioso para operar, além de estar sempre na dependência de um país estrangeiro quanto a peças sobressalentes. Tal situação acarretaria 0 atraso do desenvolvimento da indústria aeronáutica brasileira, impedindo a sua independência, porque protelaria a necessidade de recorrer à produção nacional. Finalmente, se o Brasil procurasse orientar a sua aviação comercial para o transporte de carga a bai xo custo, essa aviação não seria concorrente da aviação inglesa ou da norte-americana, mas complementar, e suas possibilidades seriam, por isso mesmo, ilimitadas.

Baseados nessas idéias nacionalistas, os pioneiros da Aeronáutica, orientados por professores norteamericanos, pretendiam montar um tripédeorganizações integradas - ensino, pesquisa tecnológica, indústria -, de modo a assegurar a possibilidadedo desenvolvimento industrial no campo da aviação.

$\mathrm{N}$ a visão do brigadeiro $\mathrm{M}$ ontenegro, que cursara engenharia aeronáutica na França, nada aconteceria na indústria aeronáutica senão se formassem técnicos brasileiros de excelência; para isso tentou, sem sucesso, convencer as universidades brasileiras a montar cursos de engenharia aeronáutica: do tripé mencionado acima, M ontenegro esua equipe priorizaram o ensino, a formação de engenheiros especializados, como o primeiro passo para a futura constituição da indústria. A solução encontrada foi um convênio com o M assachusetts Institute of Technology para a constituição de uma escola 
de engenharia aeronáutica no Brasil, o futuro Instituto Tecnológico de Ae ronáutica, ITA. U ma missão de professores do M IT veio ao Brasil com esse objetivo e a escola começou a funcionar em 1948, no Instituto M ilitar de Engenharia, na Praia Vermelha, Rio de Janeiro, enquanto não estava pronto 0 campus em São J osé dos $C$ ampos.

A criação formal da instituição se deu pelo D ecreto 27.695 de 16 de janeiro de 1950:

Art. 1ํ - O s atuais cursos de Preparação e Curso de Formação de engenheiros de Aeronáutica ficam transformados, respectivamente, em Curso Fundamental eC urso Profissional do Instituto Tecnológico de Aeronáutica.

Art. 2 - 0 ITA, que faz parte do Centro Tecnológico de Aeronáutica, [...] funcionará a partir do ano de 1950, provisoriamente, na Capital Federal, efetuando-se sua transferência para São J osé dos Campos tão logo o permitam as obras do C entro Tecnológico de Aeronáutica (apud Fischetti, 2000, p. 14).

A missão estrangeira que veio formar o ITA era composta de professores de várias nacionalidades, apesar da predominância norte-americana ou de alemães radicados nos Estados U nidos depois da guerra. Entre eles estavam Francis D ominic M urnaghan (autoridade mundial em M atemática), Theodor Theodorsen (conhecido mundialmente na área da Aerodinâmica), Charles Ingram Stanton, F. C. Phillips, J. Younger, R. N. D ubois, T. V. Jones, e os alemães do departamento de M ecânica, H einrich Peters, 0 tto Weinbaum e W. Kotenberg. Para trabalhar com os especialistas estrangeiros e depois substituí-los, o M inistério da Aeronáutica contratou eminentes professores brasileiros, entre os quais Fernando Pessoa Rebello, Jacek Piotr G orecki, Paulo Ernesto Tolle, Paulus Aulus Pompéia, 0 ctávio Gaspar de Souza Ricardo, Jeremias Chrispim e Álvaro M iguez Bastos da Silva.

Depois de alguns anos do início das atividades do ITA, foi constituído 0 órgão do qual o instituto formalmente fazia parte, ou seja, o Centro Tecnológico de Aeronáutica. 0 CTA tinha por objetivos: ministrar o ensino de grau universitário correspondente às atividades de interesse para a aviação nacional e, em particular, para a Força Aérea Brasileira; promover, estimular, conduzir e executar a investigação científica e técnica, visando ao progresso da aviação brasileira; homologar aeronaves no país; cooperar com a indústria do país para orientá-la em seu aparelhamento e aperfei çoamento, visando a atender às necessidades da Aeronáutica; colaborar com 
as organizações científicas, técnicas e de ensino do país e de outras nações, para o progresso da ciência e da técnica.

Além do M IT, o ITA inspirou-se no modelo do California Institute of Technology (C altech) e nos seus primeiros dez anos firmou-se como escola de excelência, com padrões próprios e bem diversos do tradicional sistema de ensino superior brasileiro da época. Assim, adotou a estruturação acadêmica departamental em vez do sistema de cátedras; recrutou corpos docente e discente em regime de dedicação exclusiva ao trabalho escolar; optou por currículo dinâmico e flexível, ao contrário do "currículo modeIo" adotado pelas principais escolas de engenharia do país; assumiu sua preocupação com o caráter básico e prático, e não essencialmente teórico, do ensino; introduziu matérias de H umanidades num curso de engenharia; garantiu a existência de laboratórios tanto nas disciplinas de formação básica como nas de caráter profissional.

Esse modelo influenciou a nova orientação do ensino superior brasileiro estabelecida pela Lei de Diretrizes e Bases da Educação, aprovada em fins de 1961, com reflexos inegáveis na composição do novo currículo mínimo do curso de engenharia aprovado em 1976 pelo Conselho Federal de Educação. Além disso, a qualidade dos engenheiros formados pelo ITA era louvada pelos empregadores e reconhecida pelas universidades estrangeiras que os recebiam para cursos de pós-graduação. A nova forma de ensino adotada pelo ITA, calcada no "modelo norteamericano", mostrava-se um sucesso.

No fim da década de 1950, quando o professor Samuel Steinberg era reitor do ITA, a cooperação norte-americana passou a contar também com o apoio financeiro do governo dos Estados Unidos, por meio da International Cooperation Administration, organismo mais conhecido no Brasil como Programa do Ponto Q uatro. Essa cooperação recebeu um importante impulso quando o professor $\mathrm{M}$ arco $\mathrm{C}$ ecchini, primeiro reitor de nacionalidade brasileira, que assumiu a reitoria do ITA em 1960 em substituição ao professor Steinberg, estabeleceu um convênio entre o ITA e a Universidade de M ichigan, com o apoio financeiro de 1 milhão de dólares concedido pela Agency for International Development, como parte do programa de ajuda externa conhecido como "Aliança para o Progresso". Essa cooperação terminou em 1967.

Em 1961 foi criado o Curso de Pós-Graduação, estruturado de acordo com o modelo norte-americano. Seu pioneirismo serviu de modelo para a reestruturação de toda a pós-graduação brasileira ocorrida na década de 
4. $0 \mathrm{~s}$ alunos de engenharia, selecionados entre milhares de candidatos em todo o país, recebem uma bolsa da Aeronáutica, sendo-lhes proporcionado ensino de alto nível, alimentação e acesso a todos os recursos do instituto. No primeiro ano da escola, as moças e os rapazes freqüentam também o C urso de Preparação de 0 ficiais da ReservadaAeronáutica, de forma a cumprirem as exigências do serviço militar, passando assim a integrar, como aspirantes, o quadro de engenheiros de reserva da Aeronáutica.

5. D esenvolvidos pela antiga D ivisão de Aeronaves do Instituto de Pesquisas e D esenvolvimento, atualmente incorporado ao Instituto de Aeronáutica e Espaço.
1960, inclusive nas áreas não tecnológicas. Perseguindo sempre os objetivos maiores que nortearam sua criação, o ITA tem primado pela formação de recursos humanos do mais alto padrão, nos níveis de graduação e pósgraduação ${ }^{4}$.

Esse ambiente de excelência profissional transformou a cidade de São José dos $C$ ampos ea região vizinha, no vale do Paraíba, em pólo privilegiado para o florescimento das chamadas tecnologias de ponta, sediando atualmente inúmeras indústrias, duas universidades privadas, escolas técnicas e de engenharia e o Instituto $\mathrm{N}$ acional de Pesquisas Espaciais, do M inistério da Ciência e Tecnologia.

A experiência da Aeronáutica demonstra que, ao contrário das importações de pacotes fechados de tecnologias específicas, tão apregoadas como panacéia por al gumas lideranças políticas brasileiras, um desenvolvimento científico e tecnológico autóctone, por necessitar de maior período de maturação, exige persistência e confiança no futuro, mas é capaz de assegurar o lançamento, pela indústria nacional, de produtos adequados ao mercado e capazes de sobreviver no acirrado ambiente de competição nacional e internacional.

Em 1968, anos após a criação do ITA, voava em São José dos Campos a aeronave Bandeirante, resultado de um projeto do CTA. D estacaram-se no desenvolvimento do avião vários engenheiros já formados pelo ITA, que transformaram em realidade uma das metas da Aeronáutica na época, um avião compatível com a deficiente infra-estrutura aeroportuária brasileira, principalmente no $\mathrm{C}$ entro- 0 este e região amazônica.

Todavia, uma vez concluídos os protótipos ${ }^{5}$, surgia um novo desafio: a produção seriada e a comercialização. N essa fase, a figura brilhante de um dos pioneiros diplomados pelo ITA em 1953, o brigadeiro-do-ar Paulo Victor da Silva, na época diretor-geral do CTA, conseguiu consolidar as providências para a criação da Embraer, que, sob a presidência de 0 zires Silva, oficial da Aeronáutica e "iteano", vendeu mais de quinhentos aviões Bandeirantes em todo o mundo e abriu o mercado norte-americano para os produtos aeronáuticos brasileiros.

M as a história da implantação de uma indústria aeronáutica no Brasil não estaria completa se apenas nos detivéssemos nas instituições públicas e prescindíssemos do relato de algumas experiências pioneiras conduzidas pela iniciativa privada. $\mathrm{E}$ isso nos remete a uma indagação: por que não foram os agentes privados os que encararam e resolveram o desafio da produção comercial de aeronaves? Vejamos. 
Experiências pioneiras de produção de aviões remontam, no Brasil, aos anos de 1930. N essa época, um número significativo de aviões de pequeno porte, civis e militares, já havia sido projetado e produzido. D evido ao limite do mercado interno, entretanto, o Estado (por meio dos ministérios militares) era praticamente o único comprador desses aviões. $\mathrm{N}$ as palavras de 0 zires Silva:

Parecia uma sina. O s empreendimentos nasciam por força do constante ideal de criar, construir e crescer; viviam em condições difíceis, procurando progredir fabricando produtos sabidamente complexos, sobretudo em países como o Brasil; e acabavam por fal har e morrer antes de conseguir conquistar uma cadência de produção e de vendas que auto-sustentasse os custos ligados à atividadeindustrial. Em resumo, parecia ser mais fácil conceber um novo avião, fazer voar um protótipo, que lançar uma produção seriada em condições de se manter ao longo do tempo e permanecer ancorada em um mercado de compradores razoavelmente contínuo (Silva, 1999, p. 128).

U ma dessas experiências pioneiras, que não passou de seu primeiro protótipo, o monomotor de asa alta EAY-201, foi a Empresa Aeronáutica Ypiranga, criada em São Paulo, em 1931, por H enrique Santos D umont, Fritz Roesler e O rthon W. H oover, piloto norte-americano então radicado no Brasil.

A Companhia $N$ acional de $N$ avegação Costeira (CN N A), de propriedade do armador $\mathrm{H}$ enrique Lage, foi a primeira empresa a produzir um avião em escala comercial, o bi plano detreinamento M uniz 7, com incentivo do presidente G etúlio Vargas, em 1935. 0 projeto da Ypiranga foi retomado por Lage, que produziu dois aviões inspirados naquele protótipo, o H L-1 e o CAP-4, o famoso "Paulistinha". No entanto, eles não tinham condições de competir, em preço ou qualidade, com os aviões norte-americanos, especialmente o Fairchild PT-19, que começou a ser importado durante a Segunda G uerra M undial. A companhia encerrou suas atividades em 1948.

Ainda antes da criação do M inistério da Aeronáutica, por demanda do Exército e da M arinha, que necessitavam do serviço de manutenção de seus aviões, foi feito um acordo com a empresa alemã Focke Wulf Flugzeugbau $\mathrm{G}$ mb para a montagem da Fábrica do $\mathrm{G}$ al eão. A M arinha construiu os pavilhões industriais e a empresa alemã forneceu os equipamentos e treinou mão-de-obra especializada. 0 s aviões ali montados ou produzi- 
dos eram tecnologicamente superiores aos do grupo Lage; entretanto, finda a guerra, a empresa também não conseguiu se manter em atividade.

Essas duas experiências respondiam a exigências da aviação militar, mas não foram as únicas; houve outras também na área da aviação civil. Em 1942, por exemplo, foi criada por Francisco Pignatari a Companhia Aeronáutica Paulista (CAP), e "pela primeira vez no Brasil uma empresa aeronáutica utilizou-se dos serviços de um centro de pesquisa e desenvolvimento exógeno à sua estrutura: o Instituto de Pesquisas Tecnológicas (IPT) da U niversidade de São Paulo" (C abral, 1986, p. 6). 0 maior sucesso comercial daCAP foi o "Paulistinha", monomotor deasa al ta e estilo clássico, que abasteceu a FAB e os aeroclubes de todo o Brasil, e foi exportado para Argentina, Paraguai, U ruguai, C hile, Estados U nidos, Portugal e Itália.

0 êxito desse projeto decorreu das qualidades do produto e do incentivo dado pela C ampanha $\mathrm{N}$ acional de Aviação, lançada por G etúlio Vargas em 1941 e apoiada pelos D iários Associados de Assis Chateaubriand. 0 objetivo da campanha era acelerar a formação de pilotos pela disseminação de aeronaves detreinamento nos aeroclubes do país, o que criou a demanda necessária para a elevada escala de produção do CAP-4. C om o fim da guerra foram retomadas as importações de aviões civis, em geral de maior porte, o que causou a crise da empresa, incapaz de competir com os similares importados.

O utra iniciativa igualmente fracassada foi a criação, em 1943, da Fábrica $\mathrm{N}$ acional de M otores (FN M ), originalmente idealizada para fabricar motores de avião. Foi o próprio presidente G etúlio Vargas que, negociando com as forças aliadas, especialmente o governo norte-americano, conseguiu recursos para a instalação da fábrica, oferecendo como contrapartida a participação direta do Brasil na guerra: a construção dos motores asseguraria uma reserva de mercado estratégica de produção fora da Europa e do 0 riente.

O utro fracasso foi a tentativa de fundar uma empresa aérea em Lagoa Santa, M inas G erais, por meio de um convênio entre o M inistério da Viação e $O$ bras Públicas e 0 engenheiro aeronáutico francês René C ouzinet, em 1935.

Todavia, o evento mais importante da indústria aeronáutica pré-Embraer foi a criação da Sociedade Construtora Aeronáutica N eiva, fundada pela iniciativa privada em Botucatu, na década de 1950. José C arlos N eiva montou a empresa contando com as compras governamentais e produziu alguns aviões que entraram para a história da aviação nacional: o Regente, 
primeira aeronave totalmente de metal produzida em escala industrial no Brasil, e o U niversal, um monoplano de treinamento avançado.

$\mathrm{N}$ eiva, veterano de muitas lutas, sabia do desinteresse dos capitais privados pela indústria aeronáutica brasileira e da importância da demanda governamental para sustentar sua empresa: "a dependência quase total da $N$ eiva em relação ao $M$ inistério da Aeronáutica (para quem a quase totalidade de sua produção era vendida) acabaria, no entanto, por determinar sua absorção pela Embraer em 1980" (C abral, 1986, p. 13).

Todas essas experiências pré-Embraer, apesar de sua importância, de monstram que as condições estruturais para o desenvolvimento do setor não estavam maduras. Para isso confluía um grupo importante de fatores: as limitações do mercado consumidor brasileiro, a dependência exclusiva da demanda governamental, o restrito desenvolvimento científico e tecnológico até a década de 1950, a intensa competição da indústria aeronáutica dos países desenvolvidos, a inexistência de infra-estrutura aeroportuária no país, a precariedade do parque metal-mecânico nacional e a capacidade financeira limitada dos empresários brasileiros.

É certo, como vimos, que a criação do M inistério da Aeronáutica e da Força Aérea Brasileira nos anos de 1940 e a montagem do ITA e do CTA na década seguinte haviam sido condições fundamentais e prévias para a possibilidade de instalação de uma indústria aeronáutica no Brasil. N esse sentido, a história da Embraer está imbricada na história dessas instituiç̃̃es, formando um passado comum.

0 chamado "M inistério do Ar" e a $F A B$, nascidos durante o Estado $N$ ovo e vinculados ao papel político hegemônico das Forças Armadas na sustentação do regime varguista, foram, como vimos, instituições centrais para a implementação de um projeto estratégico de desenvolvimento nacional, baseado na industrialização e na construção de um forte sistema de defesa nacional. A ligação estreita entre o desenvolvimentismo nacionalista da era Vargas, a criação da Aeronáutica e seus futuros desdobramentos, isto é, a indústria aeronáutica estatal, aparece claramente no depoimento do ex-ministro da Aeronáutica N ero M oura:

A Aeronáutica deve a G etúlio o seu nascimento, em 1941. G etúlio sempre gostou de viajar de avião, viajou muito, naturalmente, foi o primeiro presidente a viajar de avião por todo o país. Criou a Aeronáutica, nomeou o Salgado Filho ministro, apoiando-o semprena sua brilhante administração, sem dúvida facilitada pela nossa aliança com os Estados U nidos e a quantidade de material que recebemos. De 
qualquer modo, fez o máximo pela aviação durante o Estado N ovo e depois, na minha administração (1996, p. 311).

N esse sentido, com base no que expusemos, parece claro que sem essas instituições e sem um projeto estratégico nacional não haveria condições depôr em curso uma política setorial de longo prazo voltada para a formação de recursos humanos e para as atividades de pesquisa e desenvolvimento tecnológico, sem as quais o setor não poderia deslanchar. 0 s engenheiros egressos do ITA e do CTA viabilizaram a construção de uma indústria aeronáutica brasileira, dando-Ihe conotações claramente nacionalistas.

No entanto, soluções nacionalistas esbarravam na limitada capacidade financeira dos empresários brasileiros e na sua aversão ao risco de investimentos vultosos e de longa maturação. Ademais, as empresas privadas nacionais, ainda incipientes, eram prisioneiras do dilema imposto pelo descompasso e pela assincronia das políticas governamentais. U ma vez que 0 mercado interno de aviões não era protegido contra produtores estrangeiros, essas empresas tinham no próprio governo a única fonte de demanda capaz de al avancá-las economicamente.

No final dos anos de 1960, entretanto, o parque industrial brasileiro havia amadurecido, e a indústria automobilística propiciava ampla e complexa rede de apoio que removia parcialmente o obstáculo da produção doméstica de materiais e de componentes requerida para a manufatura de aeronaves. N esse momento, o novo sal to no projeto da indústria aeronáutica brasileira passou a ser apoiado pelo regime militar de 1964, possibilitando assim as condições para a criação da E mbraer. M ais uma vez, e tal como nos anos de 1940, coube a uma ditadura com forte participação dos militares tomar a decisão estratégica de criar uma indústria aeronáutica no Brasil.

Referências Bibliográficas

BernaRdes, Roberto. (2000), Embraer: elos entre Estado e mercado. Rio de Janeiro, H ucitec/Fapesp.

Botelho, Antonio José Junqueira. (1999), “D a utopia tecnológica aos desafios da política científica e tecnológica: o Instituto Tecnológico de Aeronáutica (19471967)". Revista Brasileira de Ciências Sociais, 14 (39).

Bотецh O, M aurício. (2000), Embraer: thegl obal leader in regi onal jets. $\mathrm{H}$ arvard, $\mathrm{H}$ arvard Business School, case N 9-701-006. 
Cabral, A. S. \& Braga, C. A. P. (1986), “O Estado e o desenvolvimento tecnológico da indústria aeronáutica brasileira". São Paulo, FEA/U SP, Texto de discussão n. $23 / 86$.

Cam pos Coelho, Edmundo. (1976), Em busca de identidade: o Exército ea política na sociedade brasileira. Rio de Janeiro, Forense Universitária.

CARvalho, general Estevão Leitão de. (1959), Dever militar e política partidária. São Paulo, Companhia Editora N acional.

Coutinho, Lourival. (1955), 0 general Góes depõe. Rio de Janeiro, Livraria Editora Coelho Branco.

D agn In O, R. (1987), Brazilian aeronautic industry. Campinas, Unicamp (mimeo.). Fern and des, H eloisa. (1978), O s militares como categoria social. São Paulo, Global.

FIn ER, Samuel. (1962), The man on horseback: the role of military in politics. London, Pall M all.

Fischetti, D écio (ed.). (2000), Instituto Tecnológico de Aeronáutica - 50 anos (19502000). São Paulo, Gráfica M elhoramentos.

Forjaz, M aria Cecília Spina. (1988), Tenentismo e Forças Armadas na Revolução de 30. Rio de Janeiro, Forense Universitária.

Gonı, U ki. (2002), The real O dessa: how Perón brought the nazi war criminals to Argentina. London, Granta.

H ILTON, Stanley E. (1973), "M ilitary influence on Brazilian economic policy, 19301945: a different view". H ispanic-American H istorical Review, 53, fev.

In stituto H istórico-Cultural da Aeronáutica. (1990), H istória geral da Aeronáutica brasileira. Belo H orizonte, Itatiaia/Incaer.

JAN OWITZ, M orris. (1960), The professional soldier: social and political portrait. New York, The Free Press of Glencoe.

Jornson, John. (1966), M ilitares y sociedad en América Latina. Buenos Aires, Solar/ $\mathrm{H}$ achette.

LaVen ÉRe-W Anderley, tenente-brigadeiro N elson Freire. (1975), H istória da Força Aérea brasileira. Rio de Janeiro, Escola de Guerra Naval.

LeVINE, Robert. (1980), 0 regime deVargas, 1934-1938: os anos críticos. Rio de Janeiro, N ova Fronteira.

M CC AN N , Frank D . (1980), A influência estrangei ra e o Exército brasileiro, 1905-1945. Rio de Janeiro, CPDOC/FGV.

M oreIRA, Regina da Luz. (2000), CSN : um sonho fei to de aço e ousadia. Rio de Janeiro, CPD O C/Fundação CSN .

M oura, N ero. (1996), U m vôo na história. Rio de Janeiro, Fundação G etúlio Vargas.

O liveira, Eliézer Rizzo de. (1987), As Forças Armadas no Brasil. Rio de Janeiro, Espaço e Tempo. 
O liveira, Lúcia Lippi de. (1982), Estado Novo, ideologia e poder. Rio de Janeiro, Zahar.

Rou quiÉ, Alain. (1980), Les Partis militaires au Brésil. Paris, Presses de la Fondation $\mathrm{N}$ ationale des Sciences Politiques.

Sııva, O zires. (1999), A decolagem de um sonho: a história da criação da Embraer. São Paulo, Lemos Editorial.

SOdré, N elson Werneck. (1968), H istória militar do Brasil. Rio de Janeiro, Civilização Brasileira.

Szm ReCSAnyI, Tomás \& M aranhão, Ricardo (orgs.). (2002), H istória de empresas e desenvolvimento econômico. São Paulo, Edusp/H ucitec/Imprensa O ficial.

T RoncA, Italo. (1981), "O Exército e a industrialização: entre as armas e Volta Redonda (1930-1942)". In: FAusto, Boris (org.). H istória geral da civilização brasileira. Tomo III: O Brasil republicano. São Paulo, Difel.

W IRTH, John D . (1973), A política do desenvolvimento na era Vargas. Rio de Janeiro, Editora da FGV.

\section{Resumo}

As origens da Embraer

Este artigo analisa a criação das organizações que deram origem à Embraer, isto é, o M inistério da Aeronáutica, o Centro Tecnológico de Aeronáutica (CTA) e o Instituto

Texto recebido em 5/ 2/2004 eaprovado em 28/4/2004.

M aria C ecília Spina Forjaz é mestre em Sociologia e doutora em CiênciaPolíticanaUniversidade de São Paulo. Publicou livros sobre o tenentismo e vários artigosem revistas deciências sociais. É professora titular do departamento de Ciências Sociais da Escola de Administração deEmpre sasdeSão Paulo daFundação G etúlio Vargas. E-mail: mforjaz@fgvs p.br.
Tecnológico da Aeronáutica (ITA), fundados nos anos de 1940 e 1950. Essas organizações criaram as condições para a fundação da empresa estatal em 1969. São analisadas as suas relações com o projeto estratégico de defesa nacional da Aeronáutica.

Palavras-chave: Aeronáutica brasileira; Forças Armadas e política; H istória empresarial; Estado e economia.

\section{Abstract}

The origins of Embraer

The article analyses the emergence of organizations that originated Embraer, i.e., the $M$ inistry of Aeronautics, the Aeronautics Technological Center (CTA) and the Aeronautics Technological Institute (ITA), founded in the 1940's and 1950's. These organizations made it possible for the state enterprise to come into existence in 1969. This paper analyses the Embraer's involvement with the Aeronautics' national defense strategic project.

Keywords: Brazilian Air Force; Armes and politics; Corporate history; State and economy. 